\title{
ESENSI MAQASHID SYARI 'AH DALAM KURIKULUM DAN PEMBELAJARAN FIQIH
}

\author{
Nurul Afifah \\ Institu Agama Islam Negeri Metro \\ E-mail: afiefah2278@yahoo.com
}

\begin{abstract}
Abstrak
Kurikulum merupakan salah satu komponen penting dalam proses pembelajaran. Ia digunakan sebagai pijakan dalam pelaksanaan pembelajaran serta tujuan pembelajaran bagi seorang pendidik. Faktanya kurikulum fiqih di STAIN Jurai Siwo Metro masih berkutat pada kemampuan deklaratif dan prosedural sebagaimana yang tertuang dalam SK dan KD silabus dan krikulum. Hal ini berakibat pada kurang menariknya materi fiqih dan tidak adanya atsar (efek) bagi mereka. Mensikapi permasalahan tersebut penting kiranya penelitian ini dilaksanakan dengan tujuan untuk mengetahui bagaimana esensi maqashid syari'ah dalam kurikulum fiqih prodi PGMI STAIN Metro dan bagaimana konsep pembelajaran yang sesuai dengan materi tersebut.

Penelitian ini termasuk studi pustaka dengan pendekatan kualitatif bersifat rasionalistik yang menuntut sifat holistik. Sumber data terdiri atas sumber data primer dan sekunder. Tehnik pengumpulan data melaui 5 tahapan, yaitu : Mencari literatur, mengklasifikasi buku, mengutip data, selanjutnya melakukan konfirmasi dari sumber atau dengan sumber, dan mengelompokkan data berdasarkan sistematika penelitian yang telah disiapkan. Tehnik analisis data dengan cara hermeneutic.

Hasil penelitian ini adalah konsep pembelajaran yang dipandang efektif dan efisien dalam menyampaikan materi fiqih yang berbasiskan maqashid syari'ah, yaitu pembelajaran yang memanfaatkan potensi otak mahasiswa, mengembangkan insigh, melibatkan emosi, mendahulukan kemampuan prosedural, meaningfull learning, dan pembelajaran yang menyenangkan. Strategi yang digunakan kolaborasi dari strategi pembelajaran inkuiri, kontekstual dan ekspositori, dengan metode ceramah, kisah, demonstrasi, resource person, resitasi dan tanya jawab. Media pembelajarannya; visual, audio, audio visual dan lingkungan. Sumber belajarnya adalah buku, majalah, buletin, internet, dan mendatangkan sumber asli (pelaku). Evaluasinya menganut prinsip kontinyuitas, keterpaduan dan holistik.
\end{abstract}

Kata Kunci: kurikulum, maqashid syari 'ah dan pembelajaran fiqih 


\section{Abstrack}

The curriculum is an important components in the learning process. It is used as a resource in the learning process and learning objectives for a theacher. But In fact, the curriculum of figh in STAIN Jurai Siwo Metro is still concerned with the declarative and procedural capabilities as contained in SK and KD syllabus and curriculum. This resulted in less interesting fiqih material and the absence of atsar (effect) for them. Mentoring the problem is important presumably this research is conducted with the aim to know how the essence maqashid syari'ah in the curriculum figh PGMI STAIN Metro and how the concept of learning in accordance with the material.

This research includes literature study with a rationalistic qualitative approach that demands holistic character. The data source consists of primary and secondary data sources. Techniques of collecting data through 5 stages, namely: Search the literature, classify the book, cite the data, then do the confirmation from the source or with the source, and grouping data based on systematic research that has been prepared. Data analysis techniques by hermeneutic.

The result of this research is the effective and efficient concept of learning in conveying the fiqih material based on maqashid syari'ah, that is learning which utilizes the brain potential students, develops insight, involves emotion, prioritizes procedural capability, meaningfull learning, and enjoyable learning. Strategies used in collaboration of inquiry, contextual and expository learning strategies, lecture method, story telling, demonstration, resource person, recitation and questioning. Learning media: visual, audio, audio visual and the environment. The learning resources are books, magazines, newsletters, internet, and resources person. Evaluation adheres to the principle of continuity, integrity and holistic.

Keywords: curriculum, maqashid shari'ah 'ah and learning figh

\section{A. PENDAHULUAN}

Dalam proses pembelajaran, ada tiga komponen penting dalam membentuk lingkungan pembelajaran, yakni; kurikulum, yang berisi materi yang akan diajarkan. Proses, yaitu bagaimana materi diajarkan. Dan produk, merupakan hasil dari proses pembelajaran.

Kurikulum sebagai salah satu instrument penting untuk mencapai tujuan pembelajaran sekaligus sebagai pedoman dalam pelaksanaan pengajaran. Dengan kurikulum pendidik bisa melihat apa kesulitan dan kelemahan dalam suatu pembelajaran yang dilaksanaknnya. Dengan demikian dia bisa mengambil tindakan yang tepat untuk pembelajaran selanjutnya. Dalam sebuah kurikulum materi pelajaran merupakan inti dalam proses pembelajaran. Karena pentingnya peran materi tersebut 
sehingga, sering terjadi proses pembelajaran diartikan sebagai proses penyampaian materi. ${ }^{1}$

Materi fiqih di perguruan tinggi, selama ini masih bersifat deklaratif dan prosedural sehngga kurang menarik bagi mahasiswa dan efek atau atsar dari pembelajaran fiqih itu tidak membekas pada jiwa mereka. Dari berbagai fakta di lapangan menunjukkan bahwa sebagian mahasiswa masih enggan melaksanakan syari'at seperti yang sudah diajarkan dalam materi fiqih. Bahkan beberapa diantara mereka tidak menghiraukan aturan dalam fiqih tersebut. Fakta lainnya dari pengamatan peneliti selama mengajar fiqih, adalah dari tahun ke tahun penguasaan dan pengetahuan mahasiswa akan materi fiqih masih relatif rendah. Hal ini dibuktkan dengan adanya mahasiswa yang belum bisa bertayamum, shalat di atas kendaraan, cara berwudhu yang benar, dan cara bersuci dari najis, do'a setelah shalat dan lain sebagainya. ${ }^{2}$

Fakta di atas pernah disinyalir oleh Harun Nasution. Beliau pernah menyatakan bahwa pendidikan agama Islam termasuk fiqih di dalamnya kurang memberikan kesadaran kepada peserta didik tentang pentingnya penerapan nilai-nilai agama dan kurangnya menciptakan kemauan dan tekad untuk mengamalkan nilainilai ajaran agama yang sudah diterimanya. ${ }^{3}$

Rasdijanah seperti yang dikutip oleh Muhaimin juga menyatakan bahwa dalam materi dan pembelajaran Fiqih lebih ditekankan pada kegiatan rutin agama (prosedural) dan kurang ditekankan pada proses pembentukan kepribadian. Fiqih cenderung sebagai tata aturan yang tidak berubah sepanjang masa dan kurang memahami jiwa dan arti penting aturan itu, sehingga siswa kurang terdorong untuk melakukan aturan dalam Fiqih tersebut. ${ }^{4}$

Ahmad makin dalam jurnalnya menjelaskan bahwa mata pelajaran fiqih di madrasah dan mata pelajaran fiqih di sekolah umum mempunyai ke-khas-an (karakter

\footnotetext{
${ }^{1}$ Wina Sanjaya, Strategi Pembelajaran Berorientasi Standar Proses Pendidikan (Jakarta: Kencana Prenada Media Group, 2008), h. 60.

2 Pengamatan ini Peneliti lakukan pada saat akan memulai pelajaran, biasanya peneliti mengadakan pre test tentang kemampuan mahasiswa akan materi yang akan di bahas. Hasilnya hampir $75 \%$ mahasiswa mempunyai pengetahuan yang masih rendah akan materi fiqih.

${ }^{3}$ Harun Nasution, Islam Rasional Gagasan Dan Pemikiran (Bandung: Mizan, 1995), h. 7.

${ }^{4}$ Ibid., h. 24.
} 
dan problem) yang berbeda dengan Mata Pelajaran/aspek lain. Oleh karenanya guru harus mengenali betul ke-khas-an tersebut dengan baik, dan mampu mencari solusinya bila muncul problem secara arif dan bijaksana. ${ }^{5}$

Menyimak permasalahan di atas, sudah selayaknya dosen dapat mengembangkan materi pembelajaran Fiqih yang ada supaya lebih bermakna bagi mahasiswa dan bisa memotivasi mereka untuk melakukan ibadah dan mu'amalah sesuai syari'at Islam. Lebih dari itu, agar mahasiswa mampu mengamalkan nilai-nilai dalam ibadah dan mu'amalah itu dalam kehidupan sehari-hari.

Materi Fiqih yang memuat tentang alasan seseorang melakukan ibadah sesuai syari'at Islam, apa tujuan dan manfaat bagi mereka yang melaksanakannya terdapat dalam fiqih maqashid al-syari'ah. Dengan memahami maqashid al-syari'ah, seseorang akan melakukan ibadah atau syari'at Islam itu tidak berdasarkan hawa nafsunya, namun berdasarkan kesadarannya sendiri sebagai makhluk Allah SWT.6 Oleh karena itu, penting sekali memasukkan muatan maqashid al-syari'ah dalam setiap materi fiqih. Tentunya seorang guru/dosen juga harus menyiapkan konsep pembelajaran yang sesuai dengan karakter materi maqashid al-syari'ah itu. Hal inilah yang menjadi alasan penulis meneliti tentang esensi maqashid al-syari'ah dalam kurikulum dan pembelajarannya bagi mahasiswa di perguruan tinggi.

\section{B. KAJIAN TEORI}

\section{Gambaran Umum Tentang Maqashid Syari'ah}

\section{a. Pengertian dan landasan maqashid syari'ah}

Secara etimologi maqashid syari'ah terdiri dari dua kata yaitu maqashid dan al-syari'ah. Maqashid adalah bentuk jamak dari maqshud yang berarti tujuan. Sedangkan syariah berasal dari kata syara'a asy-syai' yang berarti menjelaskan sesuatu. ${ }^{7}$

Secara terminologi, maqashid syari'ah menurut Imam al-Shatibi adalah :

${ }^{5}$ Ahmad Makinn. Karakteristik, Problematika dan Solusi dalam Pembelajaran PAI/Aspek Fiqih.

${ }^{6}$ Yusuf al-Qaradhawi, Fiqih Maqashid Syariah, Moderasi Islam Antara Aliran Tekstual Dan Liberal, terj. Arif Munandar Riswanto (Jakarta: Pustaka al-Kautsar, 2006), h. 18.

7 Ibid., h. 140. 


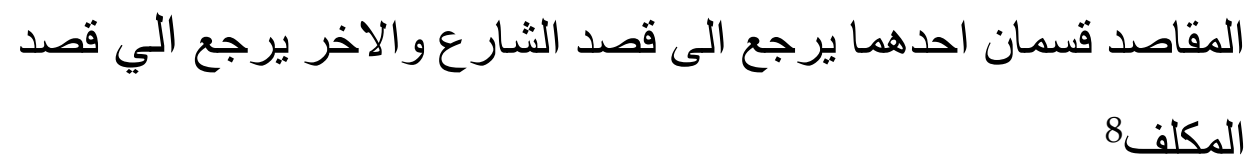

maqashid syari'ah terbagi menjadi dua yaitu; kembali kepada tujuan atau maksud Allah selaku pembuat syari'ah dan kembali kepada tujuan mukallaf itu sendiri.

Al-Shatibi juga menjelaskan bahwa maqashid syari'ah dapat mengeluarkan manusia dari kegelisahan-kegelisahan yang timbul karena nafsu dan kesenangannya, agar ia bisa menjadi hamba Allah yang baik secara pilihan maupun paksaan. ${ }^{9}$

Dari pendapat di atas dapat disimpulkan bahwa maqashid syari'ah adalah tujuan Allah Swt. selaku pembuat syar'iah untuk memberikan kemaslahatan kepada hamba-Nya baik ketika di dunia maupun di akhirat bila mereka berbuat sesuai dengan aturan syari'at Allah Swt.

Landasan dari maqashid syari'ah diantaranya adalah firman Allah Swt. dalam surat al-Nisa' ayat 165 :

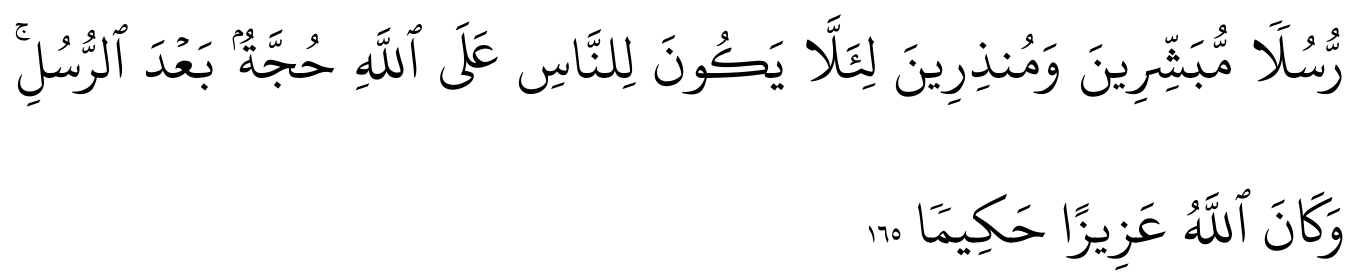

(Mereka Kami utus) selaku rasul-rasul pembawa berita gembira dan pemberi peringatan agar supaya tidak ada alasan bagi manusia membantah sesudah Allah diutusnya rasul-rasul itu. Dan adalah Allah Maha Perkasa lagi Maha Bijaksana. ${ }^{10}$

Ayat ini menunjukkan bahwa Allah Swt. dalam menentukan hukumhukumya senantiasa menghendaki sesuatu yan bermanfaat bagi manusia, sehingga bila hal tersebut tidak diusahakan manusia, maka ia akan merugi.

\footnotetext{
${ }^{8}$ Ibrahim bin musa al-Shatibi, Al-Muwafaqat Fi Usul Al-Shari 'ah (Beirut: Dar al-Kutub alAlamiyah, 2004), h. 219.

${ }^{9}$ Ibid., 221.

${ }^{10} \mathrm{QS}$, al-Nisa' (4): 165.
} 


\section{b. Obyek Kajian maqashid syari'ah.}

Obyek kajian dari maqashid syari'ah adalah kemaslahatan syari'at Islam itu sendiri. Syari'at dalam arti hukum-hukum yang sudah ditetapkan oleh Allah swt baik itu berupa perintah maupun berupa larangan.

Ibnu Qayyim seperti yang dikutip oleh Yusuf al-Qaradawi menjelaskan bahwa dasar dan asas syari'at Islam adalah kemasalahatan manusia di dunia dan di akhirat yang berupa keadilan, rahmat, dan hikmah. ${ }^{11}$

Sedangkan menurut Muhammad Abu Zahrah kemaslahatan yang dimaksud dalam maqashid syari'ah adalah maslahat yang mu'tabarat yaitu kemaslahatan yang bersifat hakiki. Kemaslahatan ini meliputi keselamatan agama, keselamatan jiwa, keselamatan akal, keselamatan keluarga dan keturunan, serta keselamatan harta benda. ${ }^{12}$

Lebih lanjut Abu Zahrah menjelaskan bahwa maslahat terdiri dari tiga tingkatan: ${ }^{13}$

1) Dharuriyat yaitu memelihara kebutuhan-kebutuhan yang bersifat esensial bagi kehidupan manusia.

2) Hajiyat yaitu kebutuhan yang dapat menghindarkan manusia dari kesulitan dalam hidupnya.

3) Tahsiniyat adalah kebutuhan yang menunjang peningkatan martabat seseorang dalam masyarakat dan di hadapan Tuhannya, sesuai dengan kepatutan.

\section{c. Tujuan mempelajari maqashid syari'ah.}

Tujuan mempelajari maqashid syari'ah adalah untuk mengetahui makna dan maksud ditetapkannya syari'at Islam. Jika maqashid syari'ah menghendaki kemaslahatan, maka secara logis maqashid syari'ah juga akan menolak kemafsadatan.

11 Yusuf al-Qaradhawi, Fiqih Maqashid Syariah, Moderasi Islam Antara Aliran Tekstual Dan Liberal, h. 76.

${ }_{12}$ Muhammad Abu Zahrah, Ushul Fiqih Terj. Saefullah Ma'sum (Jakarta: Pustaka Firdaus, 2007),

h. 425 .

${ }^{13}$ Ibid., h. 553-554. 


\section{d. Sasaran maqashid syari'ah.}

Muhammad Abu Zahrah menyebutkan ada tiga sasaran disyari'atkannya hukum Islam yaitu: ${ }^{14}$ Penyucian jiwa, menegakkan keadilan dalam masyarakat Islam, baik dengan sesama muslim maupun non muslim dan kemaslahatan Ummat.

\section{e. Pentingnya pengetahuan maqashid syari'ah.}

Pengetahuan tentang maqashid syari'ah akan memotivasi seseorang untuk melaksanakan ibadah maupun mu'amalah sesuai syari'at Islam. Selain itu dapat juga menumbuhkan keikhlasan pada diri seseorang dalam melaksanakan ibadah.

\section{PEMBAHASAN}

\section{Kurikulum Fiqih Prodi PGMI STAIN Jurai Siwo Metro}

Kedudukan kurikulum dalam pendidikan adalah sebagai pedoman pelaksana pendidikan itu sendiri. Selain itu keberadaan kurikulum sebagai fokus utama dalam perbaikan sistem pendidikan. ${ }^{15}$ Melaui perbaikan sitem pendidikan tersebut diharapkan kurikulum dapat menciptakan situasi dan kondisi konstruktif di mana siswa dapat menjadi aktif, kreatif, mandiri dan bertanggung jawab. ${ }^{16}$

Prodi PGMI merupakan salah satu prodi jurusan tarbiyah STAIN Jurai Siwo Metro. Kurikulum tahun 2014 berbasis KKNI mulai diterapkan di STAIN Jurai Siwo Metro sejak tahun ajaran 2014/2015, sebelumnya kurikulum yang diterapkan adalah kurikulum 2008. Kurikulum tahun 2014 merupakan pengembangan dari kurikulum berbasis kerangka Kualifikasi Nasional Indonesia (KKNI). Dari rumusan Kerangka Kualifikasi Nasional Indonesia (KKNI), dapat di analisa bahwa kurikulum KKNI merupakan

\footnotetext{
${ }^{14}$ Ibid., h. 543-548.

15 Nyayu Khodijah et al., “Ketepatan Penyusunan Kurikulum Prodi MPI Fakultas Ilmu Tarbiyah Dan Keguruan UIN Raden Fatah Dikaitkan Dengan KKNI Dengan KKNI, SN-DIKTI, Dan Panduan Penyusunan Kurikulum Pendidikan Tinggi Tahun 2014," El-Idare 2, no. 1 (n.d.): h. 81.

${ }^{16}$ Kholid Musyaddad, “Pengeloalaan Kurikulum,” Al-'Ulum 3, no. 1 (2014): h. 3.
} 
kurikulum yang disiapkan untuk mencetak lulusan yang siap kerja melalui pendidikan, pelatihan pengalaman kerja dan pembelajaran mandiri. Jika dilihat dari materi yang ada lebih dikhususkan materi IPTEKS (Bahasa Indonesia, Matematika, IPA, IPS, PKn) saja. Tidak ada materi keislaman sebagaimana yang tertuang di visi prodi PGMI, yaitu menghasilkan guru Kelas di MI/SD yang profesional, kreatif, mandiri serta unggul dibidang Pendidikan Dasar di dalam sinergi socio-eco-tehno-preneurship berlandaskan nilai-nilai keislaman dan keindonesiaan. Dengan pertimbangan tersebut kurikulum yang dipakai prodi PGMI bukanlah kurikulum KKNI secara murni, melainkan kurikulum 2014 berbasis KKNI.

Mata kuliah fiqih pada kurikulum 2008 terbagi menjadi 2, yaitu fiqih 1 dan fiqih 2. Untuk fiqih 1 bermuatan 2 sks diajarkan pada semester 2 (dua). Pada figh 1 ini merupakan penjelasan dan penjabaran dari figh ibadah, berisi penjelasan kewajiban manusia sebagai hamba Allah, kewajiban melaksanakan rukun Iman dan Islam, beserta konsekuensi dari pelanggaran kewajiban tersebut. Sedangkan fiqih 2 bermuatan 3 sks diajarkan di semester 3 (tiga) bermuatan tentang muamalah, munakahat, jinayah (hukum pidana dalam Islam), mawaris, dan politik dalam Islam.

Pada kurikulum 2014 berbasis KKNI prodi PGMI STAIN Jurai Siwo Metro mata kuliah fiqih dirubah namanya menjadi fiqih ibadah. Mata kuliah ini bermuatan 2 sks dan diajarkan pada semester satu. Perubahan nama dan muatan mata kulaih fiqih tersebut karena untuk memenuhi kebutuhan materi fiqih di tingkat sekolah dasar/Madrasah Ibtidaiyah. Sedangkan fiqih 2 yang semula tentang penjabaran dari ruang lingkup fiqih di ganti dengan mata kuliah Pembelajaran fiqih di MI. Mata kuliah ini bermuatan 2 sks dan berisi tentang bagaimana cara pembelajaran fiqih di MI.

Jika dibandingkan muatan kurikulum 2014 berbasis KKNI dengan kurikulum 2008 untuk mata kuliah fiqih, tentu lebih luas dan mendalam materinya pada kurikulum 2008. Namun jika dianalisa dari produk yang akan dihasilkan maka kurikulum 2014 lebih baik dari kurikulum 2008. Keterbatasan materi fiqih dalam kurikulum 2014 tentunya membawa dampak 
terbatasnya pengetahuan mahasiswa akan ilmu fiqih. Untuk mengatasi keterbatasan tersebut dosen fiqih menambahkan materi diluar kurikulum pada saat pembelajaran di kelas.

Melihat fakta di lapangan yang menunjukkan masih banyak mahasiswa masih enggan melaksanakan syari'at seperti yang sudah diajarkan dalam materi fiqih. Bahkan beberapa diantara mereka tidak menghiraukan aturan dalam fiqih tersebut maka pengembangan materi fiqih berbasis maqashid syari'ah sangatlah penting. Hal ini bertujuan agar mahasiswa termotivasi untuk melakukan ibadah yang sudah diajarkan dengan ikhlas, menumbuhkan rasa patuh kepada Allah dan menumbuhkan kesadaran dalam diri mereka untuk mengamalkan ibadah dalam kehidupan sehari-hari

\section{Pembelajaran Fiqih di Perguruan Tinggi dan Pengembangan Materinya.}

\section{a. Pembelajaran Fiqih di Perguruan Tinggi}

Fiqh merupakan salah satu bidang ilmu yang secara khusus membahas tentang persoalan hukum yang mengatur berbagai aspek kehidupan manusia, baik kehidupan pribadi maupun bermasyarakat serta hubungan manusia dengan penciptanya. Fiqh dapat dipahami sebagai sebuah aturan main dalam kehidupan yang berporos pada al-Qur'an dan al-Hadits, meskipun sebagai sebuah formulasi hukum fiqih merupakan produk ijtihad seorang mujtahid. Ilmu fiqih berisi tentang kewajibankewajiban yang diyakini dari Allah untuk umat manusia agar manusia dapat berprilaku positif. Ketundukan manusia terhadap fiqh ini akan menjadi indikasi "kesalehan manusia" baik di hadapan Tuhannya maupun di tengah-tengah kehidupan manusia.

Pembelajaran fiqih di perguruan Tinggi khususnya di prodi pendidikan Guru Madrasah Ibtidaiyah (PGMI) disesuaikan dengan kebutuhan siswa tingkat Madrasah Ibtidaiyah yaitu tentang fiqih ibadah, oleh karena itu ruang lingkup fiqih berisi tentang Aspek Fiqih ibadah meliputi: Pengertian, ruang lingkup, tujuan dan kegunaan fiqh, ibadah mahdhoh wa ghairu mahdhoh, ketentuan dan tatacara thaharah (pengetahuan tentang najis kotoran dan istinja' serta haid, nifas dan istihadhah, wudhu, 
tayamum dan mandi, shalat fardhu dan shalat sunah, pengurusan jenazah, puasa Ramadhan dan puasa sunnah, zakat, infaq dan shadaqah, dan Haji \& umroh.

Cakupan materi fiqih pada setiap aspek seperti di atas dikembangkan dalam suasana pembelajaran yang terpadu, meliputi: Keimanan, Pengamalan, Pembiasaan, Rasional, Emosional, Fungsional, dan Keteladanan.

Penilaian hasil pembelajaran Fiqih menganut prinsip kontinuitas, yaitu dosen secara terus menerus mengikuti perkembangan, dan perubahan mahasiswa. Penilaiannya tidak saja merupakan kegiatan tes formal, melainkan juga meliputi perhatian terhadap mahasiswa ketika berdiskusi, berbicara, dan bersikap serta pengamatan ketika mahasiswa berada di ruang kelas, di tempat ibadah, dan jika diperlukan ketika mereka berada di lingkungannya.

\section{b. Pengembangan Materi Fiqih di Perguruan Tinggi.}

Seperti halnya jenis materi mata pelajaran yang lain, materi Fiqih di perguruan tinggi dapat diklasifikasi sebagai berikut:

1) Fakta, contoh cerita tentang turunnya perintah shalat, berwudhu menggunakan air, tayamum dengan debu dsb.

2) Konsep, contoh, zakat adalah harta yang wajib dikeluarkan setiap tahun karena sudah mencapai nishabnya.

3) Prinsip, contoh, seseorang yang terkena najis harus bersuci dulu bila hendak shalat.

4) Prosedur Contoh, tata cara berwudhu.

5) Sikap atau nilai

Dari kelima jenis materi di atas, yang perlu mendapat perhatian dan perlu dikembangkan adalah materi tentang sikap dan nilai, karena kedua hal ini menjadi tujuan diberikannya materi perguruan tinggi. Pengetahuan tentang nilai akan memotivasi mahasiswa untuk melakukan sesuatu yang mengandung nilai baik atau tidak melakukan sesuatu yang mengandung nilai buruk. Misalnya mengajarkan materi wudhu, selain keharusan 
menyampaikan air pada anggota tubuh, di dalamnya juga terkandung nilai-nilai kebersihan dan apa kegunaan wudhu itu untuk dirinya dan orang lain.

Ada beberapa prinsip pengembangan materi yang harus menjadi pertimbangan dosen dalam mengembangkan materi Fiqih, di antaranya adalah: Validity, Significance, Utility, Learnability dan Interest.

Sedangkan teknik penyusunan materi atau bahan ajar fiqih. melalui beberapa cara diantaranya:17 Kronologis atau berurutan, Kausal atau sebab akibat, Struktural; artinya materi disusun berdasarkan bagian-bagian tertentu; Logis dan psikologis; Spiral, artinya materi dipusatkan pada topik atau pokok bahasan tertentu. Dan hirarki belajar; artinya materi disusun berdasarkan urutan atau tahapan yang seharusnya dikuasai oleh siswa.

Keenam cara penyusunan materi di atas dapat diterapkan dalam menyusun materi Fiqih berbasiskan maqashid syari'ah. Penulis dalam penyusunan materi Fiqih berbasis maqashid syari'ah akan lebih mengutamakan penyusunan secara logis, psikologis dan spiral. Karena ketiga cara tersebut sesuai dengan karakter materi Fiqih berbasis maqashid syari'ah yang menuntut pemahaman secara logika, sesuai dengan tingkatan mahasiswa dan terfokus pada masing-masing sub bahasan.

\section{c. Unsur-Unsur Maqashid Syari'ah yang Dimasukkan dalam Pengembangan Materi Fiqih Perguruan Tinggi}

Pengembangan materi fiqih di perguruan tinggi mutlak diperlukan, hal ini disebabkan masalah- masalah yang terjadi di lapangan dimana masih banyak mahasiswa yang nota bene sudah belajar ilmu fiqih, namun mereka belum melaksanakan ruh (maqashid syari'ah) dari ilmu fiqih tersebut. Jika mereka melaksanakan ruh dari pembelajaran fiqih, tentu tidak ada lagi mahasiswa yang belum bisa bertayamum, mahasiswa yang berpakaian denga aurat terbuka ketika di luar kampus, mahasiswa yang berbuat mesum dan lain sebagainya.

\footnotetext{
${ }^{17}$ Nana Syaodih Sukmadinata, Pengembanan Kurikulum Teori Dan Praktek (Bandung: Remaja Rosdakarya, 2005), h. 105-106.
} 
Dalam pengembangan materi itu sendiri tidak bisa lepas dari unsur-unsur pokok maqashid syari'ah, karena maqashid syari'ah adalah ruh dari pembelajaran fiqih sebagaimana yang peneliti jelaskan di atas. Adapun unsur-unsur yang perlu dimasukkan dalam pengembangan materi Fiqih Perguruan Tinggi yang berbasiskan maqashid syari'ah adalah: (1) Unsur illat atau alasan mengapa mahasiswa harus melakukan suatu ibadah yang dipelajarinya. (2) Unsur maqashid atau tujuan, yaitu apa tujuan Allah memerintahkan manusia untuk melakukan suatu ibadah. Unsur tujuan ini dapat diambil dari dalil naqli maupun 'aqli. (3) Unsur maslahah atau kemaslahatan, yaitu apa saja manfaat dan hikmah melakukan suatu ibadah bagi mahasiswa baik di dunia maupun di akhirat. Kata hikmah disebut dua puluh kali dalam al-Qur'an dengan berbagai konotasi. Salah satu konosatinya adalah pemahaman terhadap rahasia-rahasia syari'at. ${ }^{18}$ Bahasan utama dalam mencari maqashid syari'ah adalah mengenai masalah hikmah dan illat. Untuk mengungkap illat dan hikmah itu dapat menggunakan akal manusia (ma'qulat al-ma'na). ${ }^{19}$

\section{Konsep Pembelajaran Fiqih yang Bermuatan Maqashid Syari'ah di Perguruan Tinggi.}

Pembelajaran sebagai sebuah sistem harus memiliki; pertama, tujuan atau hasil yang diharapkan. Kedua, proses kegiatan pembelajaran. Ketiga, pemanfaatan setiap komponen dalam proses pembelajaran untuk mencapai tujuan dan untuk mengetahui keberhasilan pencapaian tersebut. Ada beberapa komponen dalam proses pembelajaran yaitu; tujuan pembelajaran, materi pembelajaran, strategi dan metode yang digunakan, media atau sumber belajar dan evaluasi. ${ }^{20}$

Dalam menetapkan tujuan pembelajaran Fiqih berbasiskan maqashid alsyari 'ah, lebih menekankan pada alasan mengapa ibadah atau mu'amalah itu

\footnotetext{
18 Ibid., h. 155.

${ }^{19}$ Fathurrahman Djamil, Metode Ijtihad Majlis Tarjih Muhammadiyah (Jakarta: Logos Publishing House, 1995), h. 36.

${ }^{20}$ Wina Sanjaya, Strategi Pembelajaran Berorientasi Standar Proses Pendidikan, h. 58.
} 
harus dikuasai dan diamalkan oleh siswa, apa tujuan Allah mensyari'atkan ibadah atau mu'amalah itu, serta apa hikmah dan manfaatnya bagi siswa. Tujuan pembelajaran harus dibuat sejelas dan semenarik mungkin karena semakin jelas tujuan semakin kuat memberi motivasi kepada siswa.

Supaya tujuan pembelajaran Fiqih yang berbasiskan maqashid syari"ah di tingkat Perguruan Tinggi dapat tercapai dengan efektif, ada beberapa prinsip yang harus dipenuhi dalam pembelajarannya, di antaranya adalah:

1) Dosen dalam pembelajarannya harus memanfaatkan potensi otak mahasiswa. Artinya, mahasiswa diajak berpikir tentang materi yang akan dipelajari. Dalam bidang Fiqih, mahasiswa diajak berpikir tentang kenapa Allah mensyari'atkan ibadah dan mu'amalah kepada manusia serta apa manfaatnya bagi orang yang mengamalkannya. (2) Mengembangkan insight atau persepsi mahasiswa. Yaitu, pemahaman terhadap hubungan antar bagian di dalam suatu situasi permasalahan. Menurut teori Gestalt, insight adalah inti dari pembentukan tingkah laku. Salah satu prinsip teori Gestalt adalah pembelajaran bukan hanya mengembangkan intelektual saja, akan tetapi mengembangkan pribadi anak seutuhnya. Kemampuan intelektual anak diharapkan mampu membentuk sikap dan kepribadian yang baik. ${ }^{21}$

2) Melibatkan emosi mahasiswa. Artinya, dalam setiap pembelajaran Fiqih berbasis maqashid al-syariy'ah, perasaan mahasiswa harus disentuh sehingga mereka tergugah untuk melakukan apa yang sudah diajarkan oleh dosen, terutama untuk menanamkan maksud dan tujuan disyari'atkannya suatu ibadah.

3) Mendahulukan kemampuan prosedural mahasiswa, yaitu kemampuan mengenai cara melakukan sesuatu atau berbuat sesuatu. Dalam bidang Fiqih, kemampuan prosedural ini ditunjukkan seperti kemampuan melakukan wudhu', shalat, dzikr, berdoa dan

${ }^{21}$ Ibid., h. 120. 
sebagainya. Kemampuan prosedural ini harus benar-benar dikuasai oleh mahasiswa sebelum masuk ke materi maqashid al-syari'ah.

4) Pembelajarannya penuh makna (meaningfull learning).

5) Pembelajarannya menyenangkan.

Strategi pembelajaran yang sesuai untuk digunakan dalam pembelajaran Fiqih berbasiskan maqashid syari'ah, adalah strategi pembelajaran inkuiri, strategi pembelajaran kontekstual dan strategi pembelajaran ekspositori. Penerapan strategi pembelajaran dapat dikolaborasikan antara satu strategi dengan strategi yang lainnya. Sehingga dalam pembelajaran bisa menerapkan banyak strategi yang bisa mencapai tujuan pembelajaran secara efektif dan efisien.

Dari tiga strategi pembelajaran di atas, dapat disimpulkan bahwa metode pembelajaran yang paling efektif untuk materi Fiqih Perguruan Tinggi berbasiskan maqashid al-syari 'ah adalah metode ceramah, kisah/ibrah, demonstrasi, resource person, tanya jawab dan diskusi serta metode resitasi. Metode-metode itu diterapkan secara berkolaborasi, saling menunjang dan melengkapi dalam mencapai tujuan pembelajaran.

Media pembelajaran yang menunjang dalam pembelajaran Fiqih berbasiskan maqashid syari'ah antara lain media visual, audio, audio visual dan alam.

Pemanfaatan media ini harus benar-benar dipergunakan oleh dosen agar tujuan pembelajaran mudah tercapai dan mahasiswa termotivasi untuk melakukan hal-hal yang dianjurkan oleh dosen. Media yang paling efektif untuk mencapai tujuan pembelajaran fiqih berbasis maqashid syari'ah di perguruan tinggi adalah audio visual dan alam karena sangat menyentuh emosi mahasiswa.

Sedangkan sumber belajar dalam pembelajaran Fiqih berbasiskan maqashid syariyah diantaranya adalah : buku-buku yang memuat tentang keutamaan dan keistimewaan ibadah tertentu. Majalah, buletin atau internet yang memuat kisah tentang orang-orang yang taat beragama dan sukses 
hidupnya, Mendatangkan pelaku (nara sumber) asli. Atau mendatangkan seorang dokter dan psikolog untuk menguatkan penjelasan dosen.

Evaluasi materi fiqih yang berbasiskan maqashid syari'ah tidak cukup hanya di dalam kelas, namun juga di luar kelas seperti di lingkungan kampus, masyarakat dan di rumah. Hal ini diperlukan untuk mengetahui gambaran yang utuh tentang pemahaman dan aplikasi pemahaman mahasiswa terhadap satu materi fiqih dalam kehidupan sehari-hari.

Ada beberapa prinsip yang harus diperhatikan oleh dosen dalam mengevaluasi tingkat pemahaman mahasiswa yang sudah menerima materi fiqih berbasiskan maqashid syari'ah, yaitu; a. Prinsip kontinuitas (terus mengikuti pertumbuhan), b. Prinsip keterpaduan (semua pihak diajak untuk mengevaluasi mahaiswa) dan c. Bersifat holistik, (menyeluruh dari tiga ranah yaitu kognitif, afektif dan psikomotorik).

\section{SIMPULAN}

1. Pengembangan materi fiqih bermuatan maqashid syari'ah dalam kurikulum 2014 sangatlah penting. Dengan mengetahui maqashid syari'ah, mahasiswa akan termotivasi untuk melakukan ibadah yang sudah diajarkan dengan ikhlas, menumbuhkan rasa patuh kepada Allah dan menumbuhkan kesadaran dalam diri mereka untuk mengamalkan ibadah dalam kehidupan sehari-hari.

2. Konsep pembelajaran fiqih bermuatan maqashid syari'ah. meliputi;

a. Menentukan tujuan pembelajaran yang lebih menekankan pada kemampuan mahasiswa, mampu memahami pentingnya ibadah, tujuan Allah mensyari'atkan ibadah, serta manfaat dan hikmah ibadah.

b. Untuk mencapai tujuan di atas prinsip pembelajaran yang harus diperhatikan adalah; memanfaatkan potensi otak mahasiswa, mengembangkan insight mahasiswa, melibatkan emosi, mendahulukan kemampuan prosedural, meaningfull learning dan pembelajaran yang menyenangkan. Sedangkan strategi yang bisa digunakan adalah; strategi pembelajaran inkuiri, kontekstual dan ekspositori. Metode yang diterapkan adalah ceramah, kisah, demonstrasi, resource person, tanya 
jawab dan diskusi serta resitasi. Media pembelajarannya bisa visual, audio, audio visual dan lingkungan. Sedangkan sumber belajarnya adalah buku, majalah, buletin, internet, mendatangkan sumber asli. Evaluasinya menganut prinsip kontinyuitas, keterpaduan dan holistik.

\section{DAFTAR PUSTAKA}

Fathurrahman Djamil. Metode Ijtihad Majlis Tarjih Muhammadiyah. Jakarta: Logos Publishing House, 1995.

Harun Nasution. Islam Rasional Gagasan Dan Pemikiran. Bandung: Mizan, 1995.

Ibrahim bin musa al-Shatibi. Al-Muwafaqat Fi Usul Al-Shari 'ah. Beirut: Dar al-Kutub alAlamiyah, 2004.

Kholid Musyaddad. “Pengeloalaan Kurikulum.” Al-'Ulum 3, no. 1 (2014).

Muhammad Abu Zahrah. Ushul Fiqih Terj. Saefullah Ma'sum. Jakarta: Pustaka Firdaus, 2007.

Nana Syaodih Sukmadinata. Pengembanan Kurikulum Teori Dan Praktek. Bandung: Remaja Rosdakarya, 2005.

Nyayu Khodijah, Febriyanti, Saiful Annur, and Najib Haitami. “Ketepatan Penyusunan Kurikulum Prodi MPI Fakultas Ilmu Tarbiyah Dan Keguruan UIN Raden Fatah Dikaitkan Dengan KKNI Dengan KKNI, SN-DIKTI, Dan Panduan Penyusunan Kurikulum Pendidikan Tinggi Tahun 2014." El-Idare 2, no. 1 (n.d.).

Wina Sanjaya. Strategi Pembelajaran Berorientasi Standar Proses Pendidikan. Jakarta: Kencana Prenada Media Group, 2008.

Yusuf al-Qaradhawi. Fiqih Maqashid Syariah, Moderasi Islam Antara Aliran Tekstual Dan Liberal. Jakarta: Pustaka al-Kautsar, 2006. 